\title{
Effects of ionization on stability of 1-methylcytosine - DFT and PCM studies
}

\author{
Ewa D. Raczyńska ${ }^{1} \cdot$ Piotr Michalec $^{2} \cdot$ Marcin Zalewski $^{2} \cdot$ Mariusz Sapula $^{3}$
}

Received: 10 February 2016 / Accepted: 26 May 2016 / Published online: 3 June 2016

(C) The Author(s) 2016. This article is published with open access at Springerlink.com

\begin{abstract}
Consequences of ionization were studied by quantum-chemical methods (DFT and PCM) for 1methylcytosine (MC) - a model of the nucleobase cytosine (C) connected with sugar in DNA. For calculations, three prototropic tautomers (one amino and two imino forms) and two imino zwitterions were considered, including conformational or configurational isomerism of exo heterogroups. Ionization and interactions between neighboring groups affect intramolecular proton-transfers, geometric and thermodynamic parameters, and electron delocalization for individual isomers. We discovered that an imino isomer is present in the isomeric mixture in the highest amount for positively ionized MC. Its contribution in neutral and negatively ionized $\mathbf{M C}$ is considerably smaller. Acid-base parameters for selected radical ions were estimated in the gas phase and compared to those of neutral MC. Gas-phase acidity of radical cations is close to that of the conjugate acid of MC, and gas-phase basicity of radical anions is close to that of the conjugate base of MC. Various routes of amino-imino conversion between neutral and ionized isomers were considered. Energetic-barrier for
\end{abstract}

Electronic supplementary material The online version of this article (doi:10.1007/s00894-016-3020-2) contains supplementary material, which is available to authorized users.

Ewa D. Raczyńska

ewa_raczynska@sggw.pl

1 Department of Chemistry, Warsaw University of Life Sciences (SGGW), 02-776 Warszawa, Poland

2 Faculty of Agriculture and Biology, SGGW, 02-776 Warszawa, Poland

3 Interdisciplinay Department of Biotechnology, SGGW, 02-776 Warszawa, Poland intramolecular proton-transfer in $\mathbf{M C}$ is close to that in the parent system-formamidine.

Keywords Acid-base parameters $\cdot$ Delocalization of $\mathrm{n}$ - and $\pi$-electrons $\cdot$ Effects of ionization $\cdot 1$-Methylcytosine $\cdot$ Prototropic tautomers and zwitterions · Tautomeric conversions

\section{Introduction}

Ionization reactions, in which a neutral molecule (M) changes its oxidation state and transforms into charged radicals, radical cation $\left(\mathrm{M}-\mathrm{e} \rightarrow \mathrm{M}^{+*}\right)$ or radical anion $\left(\mathrm{M}+\mathrm{e} \rightarrow \mathrm{M}^{-*}\right)$, are well recognized in chemistry $[1,2]$. A large number of documents can be found in the literature for simple inorganic and organic species, as well as for more complex biomolecules. Energetic parameters, called the "ionization potential" (IP) or "ionization energy" (IE) for positive ionization and the "electron affinity" (EA) for negative ionization, have been experimentally determined in the gas phase for about a thousand compounds and compiled in the NIST Chemistry Web Book, available online since 1996 [3].

Ionized forms, radical cations and radical anions, can be generated in the presence of ionizing agents, e.g., electrons, atoms, ions, etc. They can be identified in various types of mass spectrometers during positive or negative ionization [3-6]. They can also be detected by other spectroscopic techniques such as zero kinetic energy photoelectron spectroscopy [7], infrared depletion spectroscopy $[8,9]$, or time-resolved resonance Raman spectroscopy combined with pulse radiolysis [10-14]. Ionization reactions and mechanisms of one-electron loss or one-electron gain can be analyzed by quantum-chemical methods, applied to isolated (in vacuo), as well as to solvated 
molecules [15-21]. For simple molecules, the IP (or IE) and EA values are associated with an atom or group which loses or gains one-electron [15]. For more complex biomolecules, for which prototropic tautomerism coupled with resonance very often takes place, isomers favored for neutral forms not always predominate for charged radicals [22-24], and it is difficult to indicate the ionization site from simple experiments. To understand the ionization processes and to explain the mechanisms of ionization reactions for tautomeric systems, quantum-chemical calculations should be performed for complete tautomeric mixtures of neutral and ionized forms, and physicochemical properties analyzed in detail.

For free nucleobases, uracil (U), thymine (T), cytosine (C), adenine (A), guanine $(\mathrm{G})$, and for their model compounds, imidazole, purine, hydroxy- and amino-azines, the complete tautomeric mixtures in the gas phase have already been investigated [23-28]. One-electron loss and one-electron gain change acid-base properties of tautomeric groups, and consequently, change compositions of tautomeric mixtures and properties of nucleobases. These effects shed light on chemical changes in DNA, affecting aging processes, as well as various diseases, tumors, and cancers.

The phenomenon of prototropic tautomerism in heterocycles was already well known in the 1950s [29], when the molecular structure of nucleic acids was proposed by Watson and Crick [30]. The authors suggested that point mutations can occur in nucleic acids when canonical tautomeric forms of nucleobases change into their rare forms [31]. In normal nucleic acids, nucleobases have their canonical forms: amide and amino forms. Nevertheless, their rare tautomers, iminol, and imino forms are also possible (Fig. 1). In normal DNA, cytosine (C) is paired with guanine $(\mathbf{G})$, and thymine (T) is paired with adenine (A) [30]. However, the pairing can be impossible when the tautomeric preferences change. For example, the rare isomer of cytosine can be paired with adenine, and during DNA replication it can be replaced by thymine leading to the $\mathbf{G C} \rightarrow \mathbf{A T}$ transition [31]. Mispairs can also take place when one of the bases is ionized [32]. This type of mispair seems to occur most frequently than the mispairs being a consequence of neutral rare forms.

DNA mutations were theoretically modeled by Löwdin in the 1960s [33, 34]. Taking the Watson and Crick hypothesis into account, the author proposed a model in which a double intermolecular proton-transfer in base pair GC or AT is possible. This proton-transfer can change the canonical forms of nucleobases into their rare forms. Consequently, after multiple DNA replications the GC pair can be substituted by the AT pair and vice versa. This pioneering model of double intermolecular protontransfer for neutral and ionized pairs has been extensively studied by various quantum-chemical methods in the last 20 years. Some representative reports are cited here [32, 35-55]. Kumar and Sevilla [32], reviewing changes occurring in DNA exposed to high-energy radiation, paid attention to very fast $(<20 \mathrm{~ns})$ proton-coupled electrontransfer and discussed numerous experimental and theoretical works on intermolecular proton-transfer for radical ions. The authors found that in frozen aqueous solution upon one-electron loss a nucleobase becomes more acidic and can be deprotonated by a base, and upon one-electron gain it becomes more basic and can be protonated by an acid [56].

However, in the gas phase and in less polar environments, such as lipids and proteins present in living organisms, acidbase properties and proton-transfer reactions can be different from those in aqueous solution. For example, in aqueous solution amino acids and peptides exist in their zwitterionic forms, whereas in the gas phase intramolecular proton-transfers from acidic to basic groups for amphiprotic compounds are prohibited $\left(\Delta G>100 \mathrm{kcal} \mathrm{mol}^{-1}\right)$ [57]. Another example is guanidine which is a very strong base in aqueous solution $\left(\mathrm{p} K_{\mathrm{a}}>13\right)$, whereas in the gas phase its basicity is lower than that of triethylamine [3, 58]. Hence, it is possible that acid-base properties of radical ions, their stabilities and reactivities can be different in the gas phase than in aqueous solution.
Fig. 1 Canonical (G, C, A, and T) and rare forms $\left(\mathbf{G}^{*}, \mathbf{C}^{*}, \mathbf{A}^{*}\right.$, and $\left.\mathbf{T}^{*}\right)$ of nucleobases

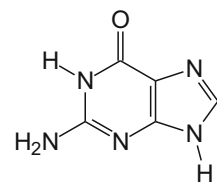

G<smiles>Nc1nc(O)c2nc[nH]c2n1</smiles>

G*<smiles>Nc1cc[nH]c(=O)n1</smiles>

C<smiles></smiles>

C*

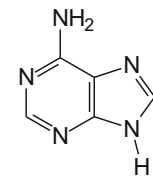

A<smiles>N=c1[nH]cnc2[nH]cnc12</smiles>

A*<smiles>Cc1c[nH]c(=O)[nH]c1=O</smiles>

T<smiles>Cc1c[nH]c(=O)nc1O</smiles>

T* 
Some information on stability of gaseous radicals of nucleobases can be found in reports of Tureček [5, 6], who used MS technologies. Nevertheless, there are little data on their acid-base properties. More information can be found for hydrated radicals of nucleobases [12-14, 32, 56]. For example, Sevilla and co-workers [56] proposed singly ( $\mathrm{pH} 7-9$ ) and doubly $(\mathrm{pH}>11)$ deprotonated species for the guanine canonical radical cation in frozen aqueous solution, whereas Choi et al. [12] showed that the deprotonated guanine radical cation can be rapidly converted by protonation to a new radical cation, its tautomer. The authors employed different spectroscopic techniques. Sevilla and co-workers used ESR and UVvisible spectroscopy, whereas Choi et al. applied timeresolved resonance Raman spectroscopy combined with pulse radiolysis. The phenomena observed by Sevilla, Choi, and their co-workers clearly showed that proton-transfer reactions for ionized nucleobases, not yet paired in the DNA structure, may be crucial for better understanding various aging and disease processes. These fascinating experiments and interesting discussions between the authors [13,14], encouraged us to continue our studies on free nucleobases and their models, undertaken about ten years ago.

In this work, we chose 1-methylcytosine (MC in Chart 1) for modeling some tendencies of cytosine, combined with sugar in the DNA structure, to intramolecular proton-transfers. MC is frequently chosen to understand various properties of cytosine included in nucleic acids [59-64], because its substitution at N1 eliminates one labile proton and reduces a large number of prototropic tautomers occurring for isolated cytosine [28] to that possible for cytosine connected with sugar. This change can induce significant differences in geometric parameters and in relative stabilities of canonical and rare forms of cytosine. For our investigations, the neutral (MC), positively ionized (MC $-\mathrm{e} \rightarrow \mathbf{M C}^{+\bullet}$ ), and negatively ionized forms $\left(\mathbf{M C}+\mathrm{e} \rightarrow \mathbf{M C}^{-\bullet}\right.$ ) were taken into account.

We studied the effects of positive and negative ionization on MC isomers in two extreme environments, the gas phase and aqueous solution. Two levels of theory were chosen here: the density functional theory (DFT) method [65] with the three-parameter hybrid functional of Becke [66] and the non-local correlation functional of Lee, Yang, and Parr (B3LYP) [67], and the 6-311+G(d,p) basis set [68], and the polarizable continuum model (PCM) [69, 70]. For selected isomers, we also tested the aug-cc-pVDZ basis set [71]. The

Chart 1 Structure of 1methylcytosine (MC)
PCM model does not include typical specific interactions with water molecules. Nevertheless, the PCM results can provide information on medium-polarity effects. The B3LYP functional was recommended and applied by Schaefer and coworkers for charged forms, particularly for radical anions $[15,20,21,50,51]$, and used by Sevilla and co-workers for ionized nucleobases $[52,53,56]$. It has been successfully applied to proton-transfer reactions for mono- and polyfunctional bases $[72,73]$ as well as to tautomeric conversions for simple [74-82] and more complex tautomeric systems including ionized nucleobases and their model compounds [24-28]. The PCM method was already used for investigations of radical ions of DNA bases and also for estimations of the IPs and/or EAs in aqueous solution [19, 83-85]. More details on selection of quantum-chemical methods are given in Electronic supplementary material (ESM).

\section{Methods}

Geometries of neutral and ionized forms of 1-methylcytosine (Fig. 2) were optimized at two levels of theory \{B3LYP/6-311+ G(d,p) [65-68] and PCM(water)//B3LYP/6-311+G(d,p) [69, 70]\} using the Gaussian-03 program [86]. For selected radical anions, calculations were also carried out at the B3LYP/aug-ccpVDZ level [65-67, 71]. Thermodynamic parameters were estimated at the same level of theory which was applied to geometry optimization. Computational details are given in ESM. The geometry-based harmonic oscillator model of electron delocalization (HOMED) indices $[87,88]$ were estimated for neutral and ionized isomers of $\mathbf{M C}$ using the same parameterization as that described previously [28, 88]. Details on the HOMED estimation are given in ESM. The harmonic oscillator model of aromaticity (HOMA) index [89-91], and the harmonic oscillator model of heterocyclic electron delocalization (HOMHED) index [92] were not applied here for MC for the reasons discussed previously [24, 26].

\section{Results and discussion}

\section{Possible isomers for MC}

Similar to the canonical form of cytosine included in DNA, MC possesses one proton at $\mathrm{N} 8$ that can be intramolecularly transferred between three tautomeric atoms, N8, O7, and N3. Each proton-transfer is accompanied by migration of double bond(s) [29]. The complete tautomeric mixture for MC consists of three prototropic tautomers (1-3) (Fig. 2). Gutowski and co-workers $[23,93]$, characterizing the valence anionic states of MC, considered additionally two zwitterionic forms (4a and 5a) with the proton at $\mathrm{C} 5$ and $\mathrm{C} 6$. Rotational and/or geometric isomerism for exo groups $(-\mathrm{OH}$ and $=\mathrm{NH}$, 
<smiles>Cn1ccc(N)nc1=O</smiles>

1<smiles>Cn1ccc(=N)nc1O</smiles>

3a<smiles></smiles>

$4 a$<smiles>Cn1ccc(=N)[nH]c1=O</smiles>

2a<smiles>Cn1ccc(=N)nc1O</smiles>

$3 b$<smiles></smiles>

4b<smiles>Cn1ccc(=N)[nH]c1=O</smiles>

2b<smiles>Cn1ccc(=N)nc1O</smiles>

$3 c$<smiles>Cn1ccc(=N)nc1O</smiles>

3d<smiles>CN1[CH+]C(=N)N(C)C1=O</smiles>

$5 \mathbf{a}$<smiles>CN1C[CH+]C(N)N(C)C1=O</smiles>

5b

Fig. 2 Eleven isomers considered here for neutral and ionized 1-methylcytosine

respectively) are also possible. Hence, considering these four types of isomerism: prototropic tautomerism, formation of zwitterions, rotational and geometric isomerism, a mixture of 11 isomers of $\mathbf{M C}$ should be analyzed to obtain a complete picture of intramolecular proton-transfer. For neutral MC, zwitterionic forms probably do not exist. However, they can be stabilized by ions or free electrons [93]. They can occur for ionized (redox) forms. Analogous to cytosine, present in normal DNA, the amino isomer $\mathbf{1}$ of $\mathbf{M C}$ can be called the "canonical" tautomer [30], and the isomer $\mathbf{2 a}$, responsible for DNA mutations, can be named the "rare" form [31].

The mixture of all 11 MC isomers can only be investigated by quantum-chemical methods. Experiments give a possibility to characterize the major forms [94]. Rare isomers, and sometimes even minor ones, are undetectable for tautomeric systems. Very often, their signals, being in the background, cannot be identified. Some isomers of neutral 1methylcytosine have already been studied in various environments [95-101]. There are also a few documents on radicals [102-107] and metal complexes [108-110]. However, literature data are not complete for $\mathbf{M C}$ and only a little information can be derived on ionization effects. Even for the neutral forms, conformational or configurational isomerism of the exo groups has not always been taken into account.

\section{Geometries, charges, spin densities, and delocalization of $\mathbf{n}$ - and $\pi$-electrons}

DFT calculations showed that heavy atoms of neutral MC isomers are in the ring plane (Table S1 in ESM) indicating that $n$ - and $\pi$-electrons are well delocalized. For the amino tautomer 1, its exo $\mathrm{NH}_{2}$ group has a pyramidal conformation analogous to that in adenine and other amino derivatives of pyrimidine [24, 26, 81]. For the imino isomers $\mathbf{2 a - 3 d}$, protontransfer from N8 to N3 or $\mathrm{O} 7$ does not destroy the ring planarity. The exo groups are in the ring plane. The $\mathrm{CC}$ and $\mathrm{CX}$ ( $\mathrm{X}=\mathrm{N}$ or $\mathrm{O}$ ) bond lengths depend on position of labile proton and on isomerism of exo groups. Ionization affects the $\mathrm{CC}$ and $\mathrm{CX}$ bond lengths and the ring planarity. Similar to isolated cytosine [28], the exo $\mathrm{NH}_{2}$ group is in the ring plane for $\mathbf{1}^{+\bullet}$, while this group has a twisted pyramidal conformation for $\mathbf{1}^{-}$. The exo $=\mathrm{NH}$ and $-\mathrm{OH}$ groups are more twisted for radical anions than for radical cations. However, the dihedral angle is not larger than $12^{\circ}$.

An analysis of charge and total atomic spin densities (Table S2 in ESM) shows important differences in ionization mechanisms. One electron can be taken from different heteroatoms and/or $\pi$-bonds in MC isomers. Various sites in MC isomers can also attach one electron. Generally, the labile proton position (N8, N3, O7, C5, or C6) generates the charge distribution and unpaired spin density on other atoms. For $\mathbf{M C}^{+\bullet}$ isomers, the spin density is delocalized on the following atoms: N1 (for 1-3d), N3 (for $\mathbf{1}$ and 3a-5b), N9 (for 2a-5b), O7 (for 1, 4a and $\mathbf{4 b}$ ), and $\mathrm{C} 5$ (for 1-3d, 5a, and 5b). For $\mathbf{M C}^{-\bullet}$ isomers, the spin density is mainly carried by carbon atoms: $\mathrm{C} 2$ (for $\mathbf{3 a - 3} \mathbf{d}$ ), C4 (for 1-3d), C5 (for 3a-3d, 5a, and 5b), and C6 (for 1-2b, 4a, and 4b), but its high concentration also exists on N3 (for 1) and N9 (for $\mathbf{2 a}$ and $\mathbf{2 b}$ ). Detailed analysis showed clearly that the unpaired electron stabilizes the structures $\mathbf{4 a}, \mathbf{4 b}, \mathbf{5 a}$, and $\mathbf{5 b}$, which were not found for neutral MC as zwitterions. 
Delocalization of $\mathrm{n}$ - and $\pi$-electrons in neutral and ionized MC isomers can be quantitatively measured using the geometry-based HOMED indices. Estimations were made for geometries optimized at the DFT level for the ring (six bonds - HOMED6) and for the whole tautomeric system, including exo groups (eight bonds - HOMED8). The calculated HOMED6 and HOMED8 values are given in Table S3 (ESM). For the neutral canonical MC-isomer $1, n-\pi$ conjugation in the six-membered ring (HOMED6 $=0.768$ ) is analogous to that for the corresponding isomer of cytosine (HOMED6 $=0.785$ [28]). The HOMED8 index is slightly larger for both MC (0.779) and $\mathbf{C}(0.791)$. For the neutral imino MC-isomers 2a, 2b, and 3a-3d, electron delocalization slightly decreases, and the HOMED6 and HOMED8 indices (0.64-0.73) are lower than those for 1. Additionally, favorable and unfavorable interactions between exo and endo groups affect electron delocalization. The HOMED indices are larger for isomers with favorable interactions. These effects are more important for 1-methylcytosine than for cytosine, indicating an important geometric difference between $\mathbf{M C}$ and $\mathbf{C}$.

Positive or negative ionization decreases electron delocalization for $\mathbf{1}$, in higher degree for its radical cation $($ HOMED $8=0.599)$ than for its radical anion (HOMED8 $=0.700$ ). Ionization of imino isomers induces different effects on electron delocalization. For example, the HOMED8 indices $(>0.9)$ for $\mathbf{3 a}^{+\bullet}-\mathbf{3} \mathbf{d}^{+\bullet}$ strongly increases, while for $\mathbf{2 a}^{+\bullet}$ and $\mathbf{2} \mathbf{b}^{+\bullet}$ they slightly decrease $(<0.7)$. For radical anions, there is no important difference in the HOMED indices between $\mathbf{3} \mathbf{a}^{-\boldsymbol{*}} \mathbf{- 3 \mathbf { d } ^ { - \bullet }}$ and $\mathbf{2} \mathbf{a}^{-\boldsymbol{*}} \mathbf{- 2} \mathbf{b}^{-\boldsymbol{*}}$ (HOMED8 0.56-0.76). Nevertheless, different conformations of exo-OH group cause stronger effect on the HOMED index ( $\triangle$ HOMED8 0.18 ) than various configurations of exo $=\mathrm{NH}$ group $(\triangle$ HOMED8 $\leq 0.04)$. Moreover, the charged radicals 4a and $\mathbf{4 b}($ HOMED $8<0.5)$ are less delocalized than $\mathbf{5 a}$ and 5b (HOMED8 $>0.5$ ). Differences between the HOMED8 indices of 5a and 4a and also between the HOMED8 indices of $\mathbf{5 b}$ and $\mathbf{4 b}$ are larger for radical cations $(\triangle \mathrm{HOMED} 8>0.4)$ than for radical anions $(\triangle$ HOMED8 $<0.2)$. Due to these differences and various ionization mechanisms for individual isomers, no linear relationship exists between the geometrybased indices of positively and negatively ionized isomers of 1-methylcytosine (Fig. S1 in ESM).

It should be noted here that the HOMED indices estimated for 1-3d of $\mathbf{M C}, \mathbf{M C}^{+\bullet}$, and $\mathbf{M C}^{-\bullet}$ are not parallel to those found previously for the corresponding isomers of cytosine [28]. Lack of linear relationships between the geometry-based indices (Fig. 3) indicates that the total effect of Me, substituted at N1, is completely different for individual isomers. For example, when going from cytosine to 1-methylcytosine the HOMED8 index decreases in different degree for the neutral (by 0.012), positively (0.267), and negatively ionized (0.003) amino form 1. For the imino isomers $\mathbf{2 a}$ and $\mathbf{2} \mathbf{b}$, the HOMED8 indices

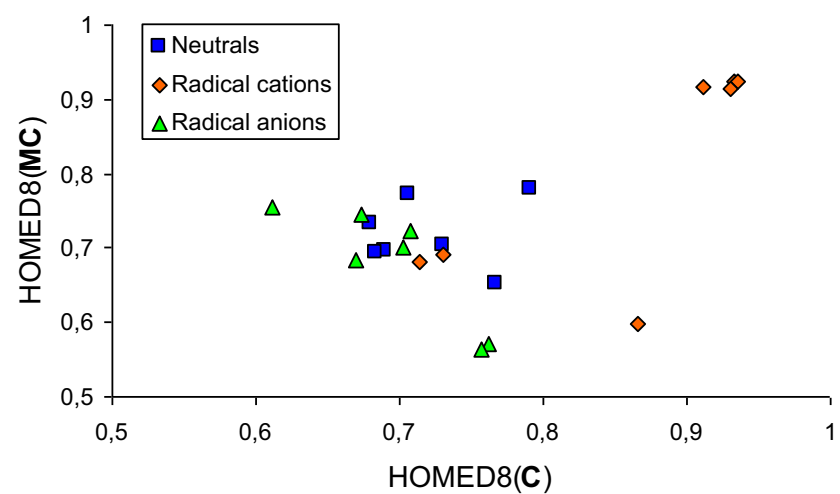

Fig. 3 Scatter plots between the HOMED8 indices of neutral and ionized isomers of 1-methylcytosine (MC) and cytosine (C)

decrease for radical cations and increase for neutral and negatively charged forms. For the imino isomers 3a-3d, variations of the HOMED8 indices depend on conformation of exo-OH group. They increase for neutral $\mathbf{3 a}$ and $\mathbf{3 c}$, and they decrease for neutral $\mathbf{3 b}$ and $\mathbf{3 d}$. Reverse

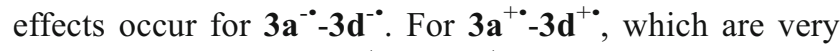
well delocalized for $\mathbf{M C}^{+\bullet}$ and $\mathbf{C}^{+\bullet}($ HOMED8 $>0.9)$, variations of the HOMED8 indices are very small $(<0.02)$.

\section{Relative thermodynamic parameters}

The isomers $\mathbf{4 a}, \mathbf{4 b}, \mathbf{5 a}$, and $\mathbf{5 b}$ (Fig. 2) exist only for positively and negatively ionized 1-methylcytosine. For neutral MC, zwitterions are unstable and during optimization the initially built isomers $\mathbf{4 a}$ and $\mathbf{4 b}$ transform into open-ring structures with the $\mathrm{N} 1-\mathrm{C} 2$ bond broken, whereas $\mathbf{5 a}$ and $\mathbf{5 b}$ go to bicyclic structures with the additional N3-C5 bond formed. The instability of the neutral isomers $\mathbf{4 a}$ and $\mathbf{5 a}$ has already been signaled [93]. For all stable isomers of MC, neutral 1-3d and ionized 1-5b, real frequencies were found for minima.

Relative thermodynamic parameters $\{\Delta(E+\mathrm{ZPE}), \Delta H$, $T \Delta S, \Delta G$ ), equilibrium constants (as $\mathrm{p} K$ ), and percentage contents (\%) estimated at the DFT level for the $\mathbf{M C}, \mathbf{M C}^{+\bullet}$, and $\mathbf{M C}^{-}$isomers in vacuo are summarized in Table $\mathrm{S} 4$ (ESM). First perusal of these values clearly indicates that the canonical form $\mathbf{1}$ is the favored isomer at each oxidation state. As could be expected [28, 93, 95-99], the isomers 3a-3d can be neglected in the isomeric mixture of neutral 1methylcytosine. The MC mixture consists mainly of three neutral isomers: 1 (97.3\%), 2a (2.6\%), and $\mathbf{2 b}(0.1 \%)$. A small amount of $\mathbf{2 a}$ and $\mathbf{2 b}$ has been detected in a frozen argon matrix [95]. Positive or negative ionization dramatically changes the composition of the isomeric mixture of $\mathbf{M C}$ in the gas phase.

Positive ionization of 1-methylcytosine affects the percentage contents of the three isomers: $\mathbf{1}(78.7 \%), \mathbf{2 a}(18.3 \%)$, and 2b $(3.0 \%)$. The isomers 3a-3d $(<0.001 \%)$ are very rare forms and can be neglected in the isomeric mixture of $\mathbf{M C}^{+}$ 
$\because$ The isomers $4 \mathbf{a}-\mathbf{5 b}\left(<1 \cdot 10^{-20} \%\right)$ have no importance for the structure and properties of $\mathbf{M C}^{+\bullet}$. Since analogous calculations were performed for isolated cytosine [28], DFT results for $\mathbf{M C}^{+\bullet}$ and $\mathbf{C}^{+\bullet}$ can be analyzed. This analysis clearly shows that stability of $\mathbf{2 a}$ strongly increases when cytosine is substituted at N1. This isomer becomes a minor one for $\mathbf{M C}^{+\bullet}$ in the gas phase, whereas it is a rare form for $\mathbf{C}^{+\bullet}(<$ $3 \%)$. For negatively ionized forms, the contribution of $\mathbf{2 a}$ in the isomeric mixture of $\mathbf{M C}^{-\bullet}(0.6 \%)$ is analogous to that for $\mathbf{C}^{-\bullet}(0.1 \%)$. Interestingly, the amounts of $\mathbf{4 a -} \mathbf{5 b}$ strongly increase for $\mathbf{M C}^{-\bullet}$, and one of them (4a, $1.8 \%$ ) cannot be neglected in the isomeric mixture. This mixture mainly contains the canonical tautomer $1(97.6 \%)$. The other imino isomers $(<0.005 \%)$ can be neglected. A use of larger basis set (aug-cc-pVDZ) in DFT calculations for the negatively ionized isomers $\mathbf{1}, \mathbf{2 a}$, and $\mathbf{4 a}$ confirms the tautomeric preference (1, $98.2 \%$ ) for $\mathbf{M C}^{-}$.

Relative thermodynamic parameters for the $\mathbf{M C}, \mathbf{M C}^{+\bullet}$, and $\mathbf{M C}^{-\bullet}$ isomers can be plotted against those previously calculated at the same level of theory for the corresponding isomers of cytosine [28]. The plots of the calculated $\Delta G$ values for $\mathbf{M C}, \mathbf{M C}^{+\bullet}$, and $\mathbf{M C}^{-\bullet}$ isomers against those for cytosine (Fig. 4) show significant differences for $\mathbf{3 b}$ and $\mathbf{3 d}$, for which the exo-OH group unfavorably interacts with Me at $\mathrm{N} 1$ in MC, and favorably interacts with N1 in C. These opposite intramolecular interactions lead to strong deviations of points referring to these two isomers. For other MC isomers, the $\Delta G$ values correlate quite well with those of the corresponding $\mathbf{C}$ isomers. For example, the slope of linear relationship for neutral isomers (1.05) and the correlation coefficient $\left(r=0.999_{9}\right)$ are close to unity. The same is true for ionized isomers, radical cations and radical anions. Generally, relative parameters for neutral and ionized isomers of 1-methylcytosine (except $\mathbf{3 b}$ and $\mathbf{3 d}$ ) are parallel to those of cytosine.

An application of the PCM(water) model to the DFToptimized geometries of $\mathbf{M C}$ isomers displays an interesting effect of medium polarity (Table S5 in ESM, ZPEs

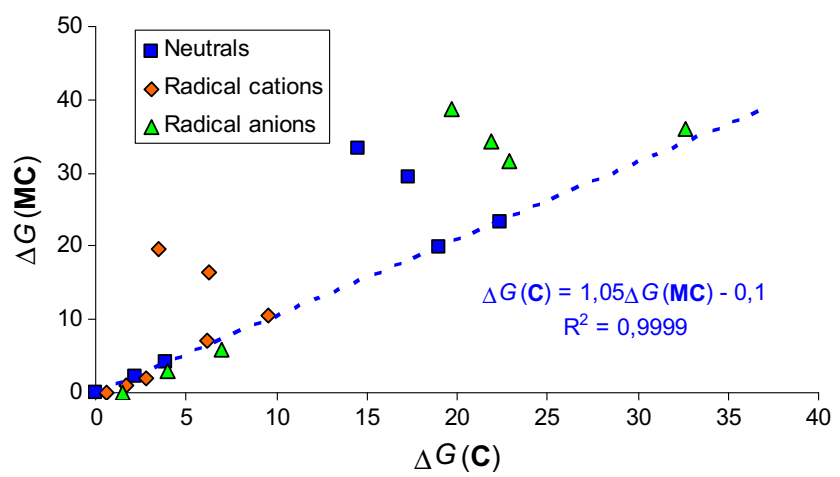

Fig. 4 Plots of the gas-phase relative Gibbs energies $\left(\Delta G\right.$ in kcal mol $\left.{ }^{-1}\right)$ of neutral and ionized forms of 1-methylcytosine (MC) against those of cytosine $(\mathbf{C})$ estimated at the DFT level were applied to the total electronic energies calculated at the PCM(water) level). For neutral MC isomers, the canonical form $\mathbf{1}$ is favored in aqueous solution $(100 \%$, assuming that thermal corrections and entropy terms in aqueous solution are the same as those in the gas phase). Relative energies of $\mathbf{2 a}$ and $\mathbf{2} \mathbf{b}$ are larger than $6 \mathrm{kcal} \mathrm{mol}^{-1}$, and thus their contributions in the isomeric mixture of neutral MC may be lower than $0.01 \%$. Relative energies of $\mathbf{3 a - 3 d}$ do not change very much when going from nonpolar (gas phase) to polar environment (aqueous solution). Their amounts can be neglected in the isomeric mixture of MC. Generally, the relative energies calculated at the $\mathrm{PCM}$ (water) level are almost parallel to those estimated at the DFT level, and a good linear relationship is found $(r=0.991)$ for neutral isomers of MC (Fig. 5). The slope of this line (0.87) is slightly lower than unity indicating some attenuation of isomerization effects in aqueous solution.

For $\mathbf{M C}^{+\bullet}$ isomers, polar solvent seems to influence tautomeric equilibria and isomeric preferences. In aqueous solution, the rare isomer $\mathbf{2 a}$ seems to be the favored one $(45.0 \%)$. Its rotamer $\mathbf{2 b}$ also contributes in the isomeric mixture $(32.0 \%)$. The canonical form $\mathbf{1}$ is rather a minor form $(22.9 \%)$. The other iminol isomers can be neglected. A change of the relative energies for $\mathbf{M C}^{+}$ isomers when going from one extreme environment to the other one slightly destroys the linear relation observed for neutral isomers (Fig. 5). Larger deviations of points are found for $\mathbf{M C}^{-\bullet}$ isomers. The canonical form $\mathbf{1}$ predominates for $\mathbf{M C}^{-\bullet}(97.9 \%)$ in aqueous solution. The contribution of the rare isomers $\mathbf{2 a}$ and $\mathbf{2} \mathbf{b}$ is very small $(<0.01 \%)$. The very rare isomers 3a-3d $(<<0.01 \%)$ can be neglected. The isomer $4 \mathrm{a}(1.7 \%)$ significantly contributes in the isomeric mixture of $\mathbf{M C}^{-*}$. The amounts of $\mathbf{4 b}$ $(0.3 \%), 5 \mathbf{a}(0.08 \%)$, and $\mathbf{5 b}(0.03 \%)$ seem to be larger than those in the gas phase but they do not exceed $0.5 \%$. Generally, polarity of water affects the relative energies of imino isomers. It also reduces differences between the relative

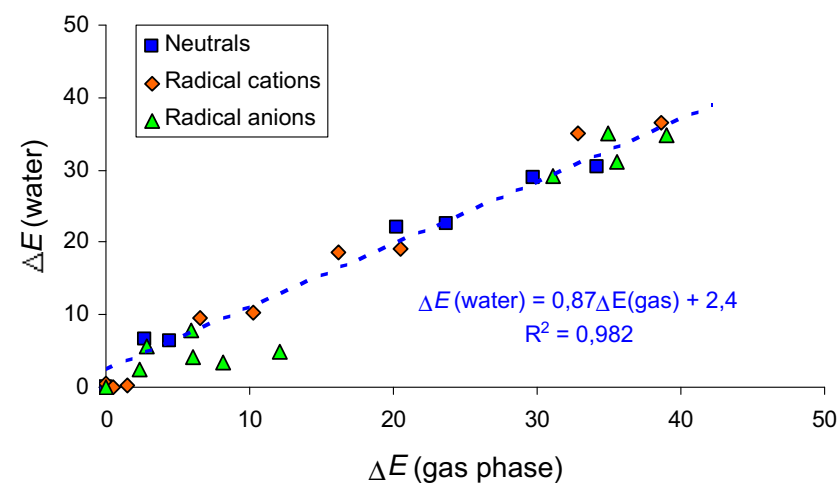

Fig. 5 Plot of the relative energies ( $\Delta E$ including $\Delta \mathrm{ZPE}$, in kcal mol ${ }^{-1}$ ) of neutral and ionized forms of 1-methylcytosine calculated in aqueous solution against those found in the gas phase 
energies for the rotamers $\mathbf{a}$ and $\mathbf{b}$ of $\mathbf{4}$ and $\mathbf{5}$ from $c a$. $6 \mathrm{kcal} \mathrm{mol}^{-1}$ in vacuo to $c a .1 \mathrm{kcal} \mathrm{mol}^{-1}$ in aqueous solution.

\section{Properties of the favored neutral and ionized isomeric mixtures}

Considering only major, minor, and rare isomers ( $>0.001 \%)$ for neutral and ionized 1-methylocytosine, the following ionization processes can be drawn (Scheme 1). In vacuo, the neutral and positively ionized isomeric mixtures of $\mathbf{M C}$ contain three isomers $(\mathbf{1}, \mathbf{2} \mathbf{a}$, and $\mathbf{2 b}$ ), whereas at least five isomers $(\mathbf{1}, \mathbf{2 a}, \mathbf{2 b}, \mathbf{4 a}$, and $\mathbf{5 a})$ can be considered for the negatively ionized molecule. For each oxidation state, the canonical isomer $\mathbf{1}$ is the favored form for 1-methylcytosine. The rare isomer 2a seems to be present in the highest amount (ca. 20\%) only for $\mathbf{M C}^{+\bullet}$. For $\mathbf{M C}$ and $\mathbf{M C}^{-\bullet}$, its contribution in the isomeric mixture is considerably lower $(<3 \%$ and $<1 \%$, respectively). In aqueous solution, composition of the isomeric mixture dramatically changes only for $\mathbf{M C}{ }^{+\bullet}$. In this case, the rare isomer $2 \mathrm{a}$ becomes the favored one ( $45 \%$ ), and the canonical isomer $\mathbf{1}$ is rather a minor form $(23 \%)$. $\mathbf{2 b}$ also has an important contribution (32\%). For neutral and negatively ionized 1-methylcytosine, the isomer $\mathbf{2 a}$ is indeed the rare form $(<1 \%)$. The isomers $\mathbf{4 a - 5} \mathbf{b}$, strongly stabilized by an unpaired electron, can also be considered as rare forms for $\mathbf{M C}^{-\bullet}(\leq 2 \%)$.

The positive and negative ionization processes can be characterized by the ionization potential (IP) and by the electron affinity (EA), respectively. Unfortunately, there are no experimental data for 1-methylcytosine. However, there are experimental data for canonical cytosine ( $\mathrm{IP}=8.45 \mathrm{eV}$ [111] and $\mathrm{EA}=0.23 \mathrm{eV}$ [112]) and for unsubstituted pyrimidine $(\mathrm{IP}=9.33 \mathrm{eV}$ [3] and $\mathrm{EA}<-0.25 \mathrm{eV}$ [113]). It should be noted that the level of theory applied here $\{(\mathrm{B} 3 \mathrm{LYP} / 6-311+\mathrm{G}(\mathrm{d}, \mathrm{p})\}$ reproduce well the IP $(9.18 \mathrm{eV})$ and EA $(-0.14 \mathrm{eV})$ for pyrimidine. Moreover, the DFT-calculated EA for pyrimidine is close to that $(-0.17 \mathrm{eV})$ found at the G3MP2B3 level [3]. This confirms that the level of theory applied here is sufficient and appropriate for neutral and ionized species, radical cations, and radical anions.

If we assume that removing or adding one electron does not very much affect the structure of MC isomers, we can calculate in vacuo and in aqueous solution the microscopic IP and EA for the individual tautomers-rotamers 1-3d, taking the energies of neutral and ionized forms into account (Table S6 in ESM). The macroscopic parameters referring to the isomeric mixture of MC (Scheme 1) can also be estimated. They are as follows: $\mathrm{IP}=8.2$ and $6.3 \mathrm{eV}$ and $\mathrm{EA}=-0.4$ and $1.8 \mathrm{eV}$ in the gas phase and aqueous solution, respectively. Polarity of water changes the ionization parameters (IP and EA) by $c a .2 \mathrm{eV}$. An analogous hydration effect has been found for nucleic acid bases and their models [16-19, 24, 26]. The negative adiabatic EA value for MC, close to that for pyrimidine [113], confirms our spin-density analysis (Table S2 in ESM). Upon negative ionization the pyrimidine ring preferentially takes one electron. Additionally, the negative EAs for MC isomers indicate that negatively ionized forms, possessing energies very close to that of neutral ones, do not exist for a suitable time period. EA measurements cannot be performed with good precision. There are also other molecules which possess negative EAs in the gas phase $[3,15,113]$. Nevertheless, they can be investigated in solution or clusters, for which the EAs are positive.

\section{Basicity and acidity of neutral and ionized MC in the gas phase}

There are no solvent molecules in the gas phase and acid-base properties of organic compounds depend only on functional groups. Acidity or basicity can be described by thermodynamic parameters of the corresponding deprotonation or protonation reaction, $\Delta H$ and $\Delta G$, which differ by the entropy term, $\Delta G=\Delta H-T \Delta S[3,114]$. For deprotonation of AH group
Scheme 1 Composition of the isomeric mixture for neutral and ionized 1-methylcytosine estimated at the B3LYP/6-311+ $G(d, p)$ level (data for selected radical anions found at the B3LYP/aug-cc-pVDZ level are given in parentheses)

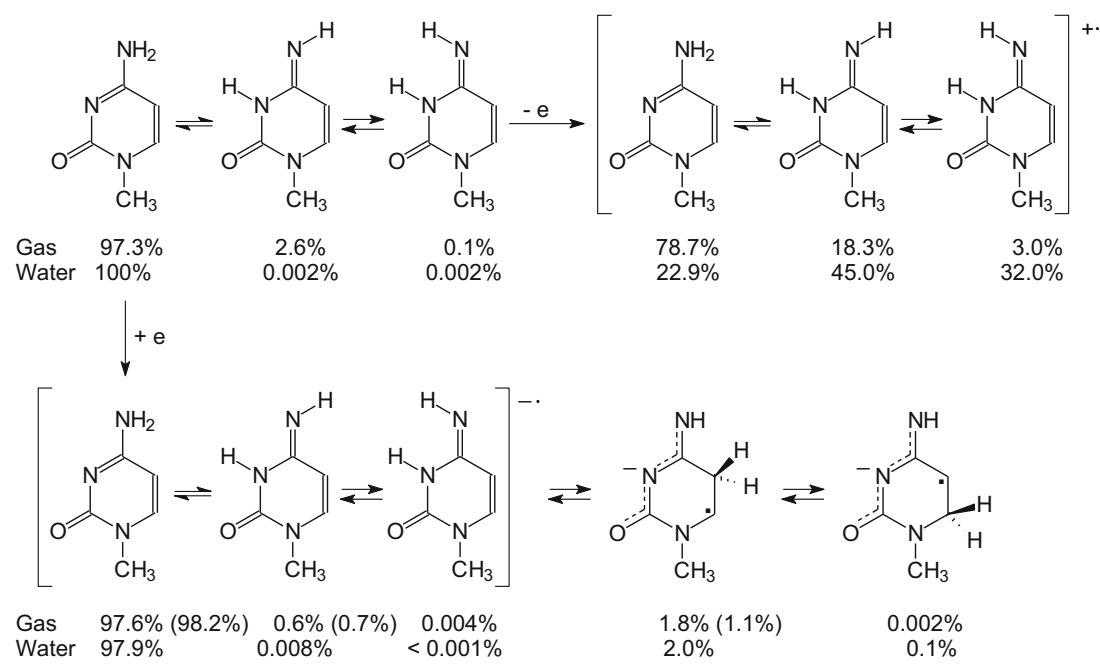


$\left(\mathrm{AH} \rightarrow \mathrm{A}^{-}+\mathrm{H}^{+}\right)$, these thermodynamic parameters refer to the deprotonation enthalpy ( $\mathrm{DPE}=\Delta H_{\text {acid }}$ ) and to the gas-phase acidity $\left(\mathrm{GA}=\Delta G_{\text {acid }}\right)$. For protonation of $\mathrm{B}$ group $\left(\mathrm{B}+\mathrm{H}^{+} \rightarrow\right.$ $\left.\mathrm{BH}^{+}\right)$, the proton affinity $\left(\mathrm{PA}=-\Delta H_{\text {base }}\right)$ and the gas-phase basicity ( $\mathrm{GB}=-\Delta G_{\text {base }}$ ) were proposed. The use of different symbols for acids and bases is only formal, because $\mathrm{DPE}(\mathrm{AH})=\mathrm{PA}\left(\mathrm{A}^{-}\right), \mathrm{GA}(\mathrm{AH})=\mathrm{GB}\left(\mathrm{A}^{-}\right), \mathrm{PA}(\mathrm{B})=\mathrm{DPE}\left(\mathrm{BH}^{+}\right)$, and $\mathrm{GB}(\mathrm{B})=\mathrm{GA}\left(\mathrm{BH}^{+}\right)$. Both, the DPE and PA values are on the same $\Delta H$ scale, and the GA and GB values are on the same $\Delta G$ scale. Stronger acid has lower DPE and GA values and stronger base has larger PA and GB values.

In the case of neutral 1-methylcytosine, experimental gasphase acidity and gas-phase basicity parameters have been determined in 2008 by Lee and co-workers [97]. The authors used a Fourier transform ion cyclotron resonance mass spectrometer and the bracketing method, and derived the following macroscopic acid-base parameters: DPE $=349 \pm 3$ and $\mathrm{GA}=342 \pm 3 \mathrm{kcal} \mathrm{mol}^{-1}$ for deprotonation of neutral $\mathbf{M C}$ to its monoanion $\mathbf{M C}-\mathbf{H}^{+}\left(\mathbf{M C} \rightarrow \mathbf{M C}-\mathbf{H}^{+}+\mathrm{H}^{+}\right)$, and $\mathbf{P A}=230$ \pm 3 and $\mathrm{GB}=223 \pm 3 \mathrm{kcal} \mathrm{mol}^{-1}$ for protonation of neutral $\mathbf{M C}$ to its monocation $\mathbf{M C H}^{+}\left(\mathbf{M C}+\mathrm{H}^{+} \rightarrow \mathbf{M C H} \mathbf{H}^{+}\right)$. Comparison of these experimental data with those found for other organic compounds in the gas phase [3] shows that 1-methylcytosine displays acidity close to that of pyrrole (DPE $=359.6$ and $\mathrm{GA}=351.8 \mathrm{kcal} \mathrm{mol}^{-1}$ ) and basicity close to that of imidazole $\left(\mathrm{PA}=225.3\right.$ and $\left.\mathrm{GB}=217.3 \mathrm{kcal} \mathrm{mol}^{-1}\right)$ and 2-aminopyridine $\left(\mathrm{PA}=226.4\right.$ and $\left.\mathrm{GB}=218.8 \mathrm{kcal} \mathrm{mol}^{-1}\right)$. Both pyrrole and 1methylcytosine belong to the family of $\mathrm{NH}$ acids, for which the NH group is deprotonated. On the other hand, imidazole, 2-aminopyridine, and 1-methylcytosine belong to the family of $\mathrm{N}$ bases which contain the amidine group $>\mathrm{N}-\mathrm{C}=\mathrm{N}-$ with the imino $\mathrm{N}$ site preferentially protonated.

Using the B3LYP functional and the $6-31+\mathrm{G}(\mathrm{d})$ basis set, Lee and co-workers [97] additionally found the following microscopic parameters for deprotonation of the neutral canonical form 1 at $\mathrm{N} 8$ and for its protonation at N3: $\mathrm{DPE}=348.3$, $\mathrm{GA}=340.3, \mathrm{PA}=230.0$, and $\mathrm{GB}=222.4 \mathrm{kcal} \mathrm{mol}^{-1}$, respectively. For the neutral rare form $\mathbf{2 a}$, these parameters for deprotonation at $\mathrm{N} 3$ and for protonation at $\mathrm{N} 8$ are as follows: $\mathrm{DPE}=350.7, \mathrm{GA}=344.5, \mathrm{PA}=232.9$, and $\mathrm{GB}=224.9 \mathrm{kcal} \mathrm{mol}^{-1}$, respectively. Deprotonation of $\mathbf{1}$ and 2a leads to the same monoanion $\mathbf{M C}-\mathbf{H}^{+}$, and their protonation goes to the same monocation $\mathbf{M C H}^{+}$(Scheme 2). For comparison, at the B3LYP/6-311+G(d,p) level we found the following values for $\mathbf{1}(355.8,347.0,232.0$, and $\left.224.2 \mathrm{kcal} \mathrm{mol}^{-1}\right)$ and $\mathbf{2 a}(353.2,344.9,234.6$, and $226.3 \mathrm{kcal} \mathrm{mol}^{-1}$ ).

To our knowledge, gas-phase acidity and gas-phase basicity for radical cations and radical anions of 1-methylcytosine have not yet been reported in the literature. Nevertheless, they can be estimated on the basis of our DFT calculations performed for selected neutral and charged radicals. According to Sevilla and co-workers experiments performed for

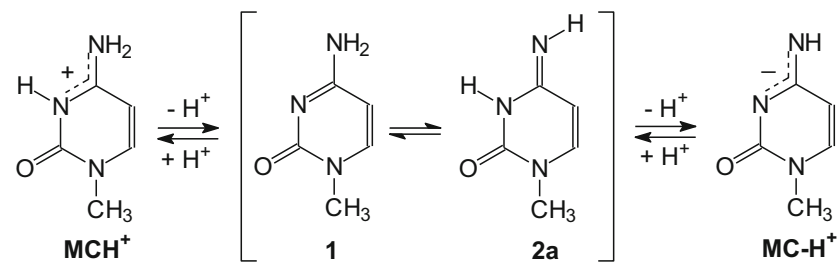

Scheme 2 Protonation/deprotonation of the neutral canonical (1) and rare (2a) isomers of 1-methylcytosine to the corresponding monocation $\left(\mathbf{M C H}{ }^{+}\right)$and monoanion $\left(\mathbf{M C}-\mathbf{H}^{+}\right)$

nucleobases and their models [32, 107], deprotonation of radical cation of 1-methylcytosine and protonation of its radical anion can lead to the corresponding neutral radical: $\mathbf{M C}^{+}$ $\cdot-\mathrm{H}^{+} \rightarrow \mathbf{M C}-\mathbf{H}^{\bullet}$ and $\mathbf{M C}^{-\bullet}+\mathrm{H}^{+} \rightarrow \mathbf{M C H}$. Acidity and basicity parameters for these deprotonation and protonation reactions in the gas phase can be predicted from the calculated thermodynamic parameters for the corresponding radicals by the same procedure applied for neutral 1-methylcytosine (see Computational details in ESM). For the canonical and rare isomers of 1-methylcytosine, their radical cations $\mathbf{1}^{+\cdot}$ and $\mathbf{2 a}^{+\bullet}$ can be deprotonated to the same neutral radical MC-H', whereas their radical anions $\mathbf{1}^{-\bullet}$ and $\mathbf{2}^{\mathbf{a}^{\bullet}}$ can be protonated to the other neutral radical $\mathbf{M C H}^{*}$ (Scheme 3). At the DFT level, the following microscopic parameters were estimated in the gas phase for these reactions (in $\left.\mathrm{kcal} \mathrm{mol}^{-1}\right)$ : $\operatorname{DPE}\left(\mathbf{1}^{+}\right.$ $\left.{ }^{\bullet}\right)=230.6, \operatorname{GA}\left(\mathbf{1}^{+\bullet}\right)=223.4, \operatorname{DPE}\left(\mathbf{2 a}^{+\bullet}\right)=230.4, \operatorname{GA}\left(\mathbf{2 a}^{+}\right.$ $\left.{ }^{\circ}\right)=222.5, \operatorname{PA}\left(\mathbf{1}^{*}\right)=350.8, \operatorname{GB}\left(\mathbf{1}^{-*}\right)=343.2, \operatorname{PA}\left(\mathbf{2 a}^{-*}\right)=353.5$, and $\operatorname{GB}\left(2 \mathbf{a}^{-*}\right)=346.2$, respectively.

Interestingly, gas-phase acidities of the radical cations $\mathbf{1}^{+\bullet}$ and $\mathbf{2 a}^{+\cdot}$ are close to that of the monocation $\mathbf{M C H}^{+}$, and gasphase basicities of the radical anions $\mathbf{1}^{-\bullet}$ and $\mathbf{2 a}^{-\bullet}$ are close to that of the monoanion $\mathbf{M C}-\mathbf{H}^{+}$. In other words, gas-phase basicity of the neutral radical $\mathbf{M C}-\mathbf{H}^{*}$ and gas-phase acidity of the neutral radical $\mathbf{M C H}^{*}$ are close to those of neutral 1-

a) deprotonation of radical cations

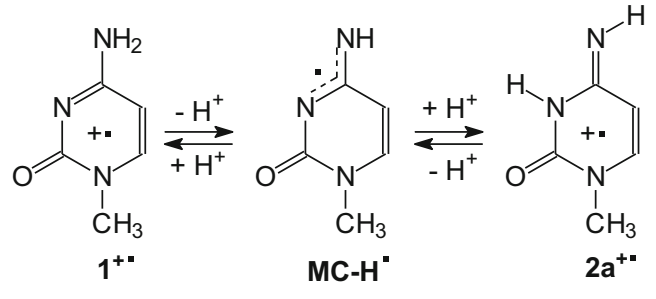

b) protonation of radical anions

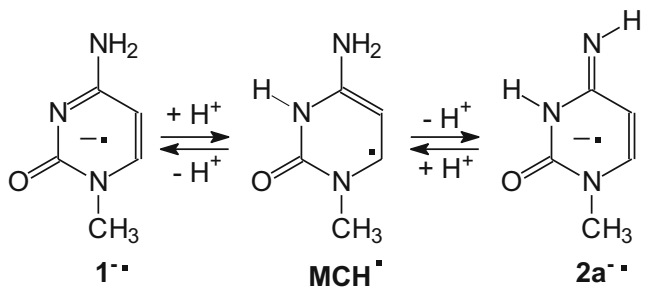

Scheme 3 Deprotonation of radical cations (a) and protonation of radical anions (b) to the corresponding neutral radicals of 1-methylcytosine 
methylcytosine (Fig. 6). Moreover, the radical cations $\mathbf{1}^{+\bullet}$ and $\mathbf{2 a}^{+\bullet}$ are stronger bases than neutral water $(\mathrm{PA}=165.2$ and $\left.\mathrm{GB}=157.7 \mathrm{kcal} \mathrm{mol}^{-1}[3]\right)$, indicating that water cannot deprotonate them in the gas phase (apolar environment). Water is too weak a base. Water is also too weak an acid $\left(\mathrm{DPE}=390.3\right.$ and $\left.\mathrm{GA}=383.7 \mathrm{kcal} \mathrm{mol}^{-1}[3]\right)$, and cannot protonate the radical anions $\mathbf{1}^{-\bullet}$ and $\mathbf{2 a}^{-{ }^{-}}$. Other compounds, being stronger bases and stronger acids than 1-methylcytosine in the gas phase, can be considered in the future for deprotonation of its radical cations and for protonation of its radical anions in an apolar environment.

\section{How the "canonical" form of MC can be converted into its "rare" form?}

Various routes can be considered for transformation of the canonical tautomer $\mathbf{1}$ into the rare isomer $\mathbf{2 a}$ for neutral and ionized 1-methylcytosine, one-step, two-steps, or multi-steps amino-imino conversion. In the gas phase, the labile proton can be transferred intramolecularly from N8 to N3 through the corresponding transition state (Scheme 4). We found three transition states between the neutral isomers $\mathbf{1}$ and $\mathbf{2 a}$ (TS) and their positively $\left(\mathbf{T S}^{+\bullet}\right)$ and negatively $\left(\mathbf{T S}^{-\bullet}\right)$ ionized forms at the DFT(B3LYP) $/ 6-311+\mathrm{G}(\mathrm{d}, \mathrm{p})$ level. Each of these transition states possesses one imaginary frequency. Inclusion of thermal corrections when proceeding from 0 to $298 \mathrm{~K}$ and entropy terms, leads to the following relative Gibbs energies (relative to the canonical tautomer) for $\mathbf{T S}, \mathbf{T S}^{+{ }^{*}}$, and $\mathbf{T S}^{-\boldsymbol{*}}$ : $\Delta G=40.4,42.0$, and $36.0 \mathrm{kcal} \mathrm{mol}^{-1}$, respectively. The estimations indicate that positive ionization slightly increases the energetic-barrier for tautomeric conversion between the amino and imino isomers whereas negative ionization slightly decreases it. Our DFT calculations show additionally that the energetic-barrier for the neutral tautomers $\mathbf{1}$ and $\mathbf{2 a}$ is slightly lower than that found by Fogarasi [76] $\left(\Delta E=45-50 \mathrm{kcal} \mathrm{mol}^{-1}\right.$ at the B3LYP, MP2, and various CC levels) for tautomeric conversion in the parent system, formamidine $(\mathrm{HN}=\mathrm{CH}$

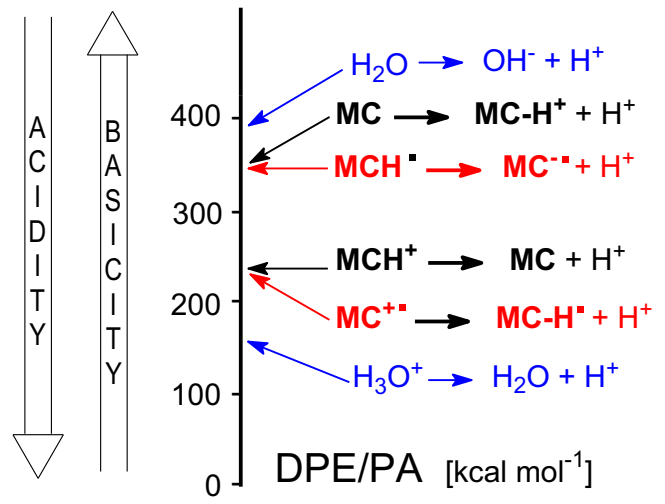

Fig. 6 Comparison of the DFT-estimated proton affinities and deprotonation enthalpies for 1-methylcytosine and its radicals with experimental data for water

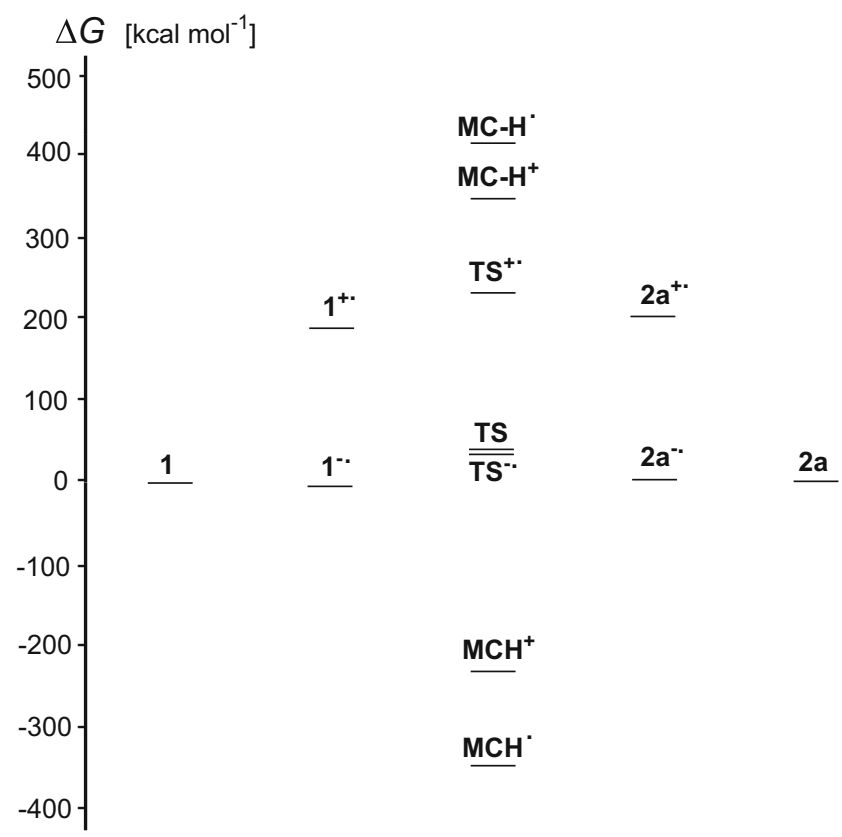

Fig. 7 Variations of the DFT-calculated relative Gibbs energies (in kcal $\mathrm{mol}^{-1}$ ) of various MC structures when going from the amino (1) to imino (2a) isomer

a) neutral isomers

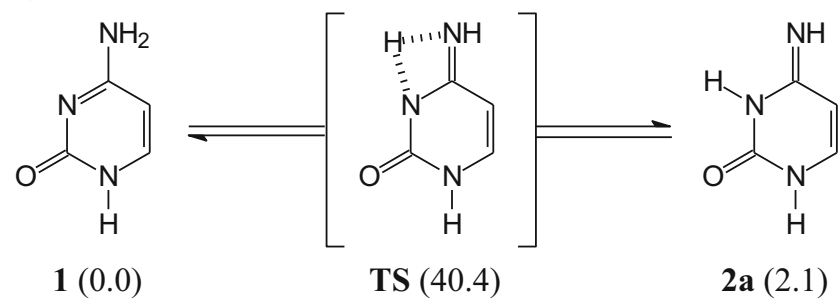

b) radical cations

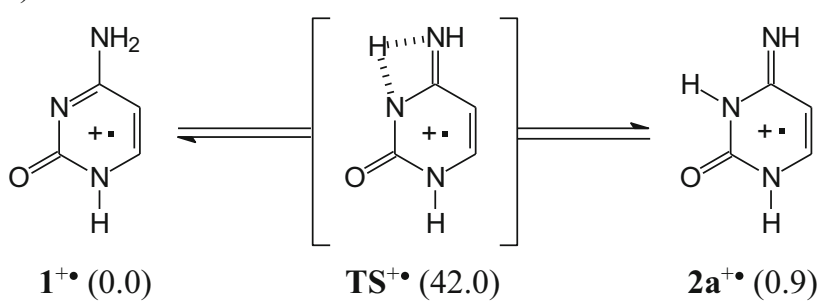

c) radical anions

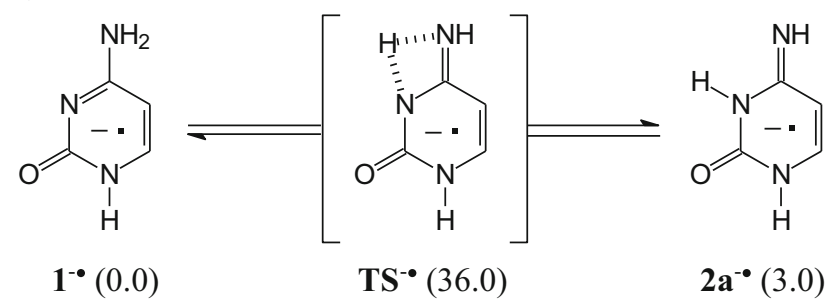

Scheme 4 One-step intramolecular proton-transfer considered in the gas phase between selected neutral (a), positively (b), and negatively ionized (c) isomers of 1-methylcytosine (relative Gibbs energies calculated at the DFT level are given in $\mathrm{kcal} \mathrm{mol}^{-1}$ ) 
$\left.-\mathrm{NH}_{2} / \mathrm{H}_{2} \mathrm{~N}-\mathrm{CH}=\mathrm{NH}\right)$. When one water molecule participates in this conversion, the energetic-barrier diminishes by 25 $30 \mathrm{kcal} \mathrm{mol}^{-1}$. An analogous decrease of the energeticbarrier for amino-imino conversion may be expected for the MC isomers.

Tautomeric amino-imino conversion between the canonical and rare tautomers of 1-methylcytosine can also run through two-steps proton-transfer reaction. For neutral forms, the monoanion $\mathbf{M C}-\mathbf{H}^{+}$or monocation $\mathbf{M C H}^{+}$can be an intermediate product between the isomers $\mathbf{1}$ and $\mathbf{2 a}$ as shown in Scheme 2. For radical ions, tautomeric conversion between $\mathbf{1}^{+\cdot}$ and $\mathbf{2 a}^{+\cdot}$ can run through the neutral radicals $\mathbf{M C}-\mathbf{H}^{\bullet}$ and that between $\mathbf{1}^{-}$and $2 \mathrm{a}^{-\bullet}$ can run through the other neutral radical $\mathbf{M C H}^{*}$ as shown in Scheme 3.

Investigating gas-phase basicities of organic compounds by quantum-chemical methods, Makisć and co-workers [72] analyzed the following steps from neutral (B) to monoprotonated $\left(\mathrm{BH}^{+}\right)$forms: positive ionization of base (B $\left.-\mathrm{e} \rightarrow \mathrm{B}^{+\cdot}\right)$, formation of hydrogen atom $\left(\mathrm{H}^{+}+\mathrm{e} \rightarrow \mathrm{H}^{*}\right)$, and formation of conjugate acid $\left(\mathrm{B}^{+\cdot}+\mathrm{H}^{*} \rightarrow \mathrm{BH}^{+}\right)$. These steps are in agreement with experiment. Gas-phase basicities can be measured using various MS techniques with positive ionization, and ions $\mathrm{B}^{+\bullet}$ and $\mathrm{BH}^{+}$detected and analyzed $[3,57,114]$. Taking into account the MS experiments and the "triadic analysis", tautomeric conversion between $\mathbf{1}$ and 2a can also run through $\mathbf{M C H}^{+}, \mathbf{1}^{+\bullet}$, and $\mathbf{2 a}^{+\bullet}$. An analogous tautomeric conversion between $\mathbf{1}$ and $\mathbf{2 a}$ can be proposed for negative ionization in the gas phase, where $\mathbf{1}^{-\boldsymbol{*}}, \mathbf{2 \mathbf { a } ^ { - \bullet }}$ and $\mathbf{M C}-\mathbf{H}^{+}$can be intermediates (Scheme 5).

Another conversion-route between the ionized canonical and rare isomer of 1-metylcytosine can be proposed on the basis of Choi et al. experiments for guanidine radical cations [12]. The authors observed the neutral radical as an intermediate between two ionized isomers. On the other hand, Sevilla, Tureček, and their co-workers [5, 6, 32, 56, 106, 107] proposed a deprotonation reaction for radical cations and protonation reaction for radical anions, both leading to the corresponding neutral radicals. Taking these experimental observations into account, tautomeric conversion between the ionized canonical and rare isomers of 1-methylcytosine can also run through $\mathbf{M C}^{-\mathbf{H}^{*}}$ or $\mathbf{M C H}^{*}$ (Scheme 6).

The route of proton-transfer between the canonical and rare isomers of 1-methylcytosine may depend on the method of investigation. For example, in matrix isolation IR, MW, and REMPI experiments, the intramolecular proton-transfer proposed in Scheme 4a may take place for the neutral isomers. During experimental MS gas-phase acidity/basicity determinations, tautomeric conversion may run through the monocation $\mathbf{M C H}^{+}$or monoanion $\mathbf{M C}-\mathbf{H}^{+}$(Scheme 5). The neutral radicals $\mathbf{M C}-\mathbf{H}^{*}$ or $\mathbf{M C H}^{*}$ may be intermediates between the radical ions (Scheme 6) in zero kinetic energy photoelectron spectroscopic studies.

\section{Conclusions}

Our calculations carried out in the gas phase at the DFT level and in aqueous solution at the PCM(water) level for the isomeric mixture of neutral and ionized 1-methylcytosine show clearly that positive and negative ionization change both the geometry- and energy-based parameters. Electron delocalization in the pyrimidine ring and also in the whole tautomeric system dictates the isomeric preference only for neutral MC. The most delocalized amino isomer $\mathbf{1}($ HOMED8 $=0.779)$ is favored for MC. When going from the neutral to charged radicals, electron delocalization changes dramatically. Due to completely different $\mathrm{Me}$ effects for individual $\mathbf{M C}$ isomers, the changes are not parallel to those observed earlier for cytosine (Fig. 3) [28]. Only relative thermodynamic parameters for MC isomers correlate well with those for the corresponding isomers of cytosine (Fig. 4). Some exceptions are the isomers
Scheme 5 Multi-steps

conversion considered in the gas phase between isomers of 1 methylcytosine via the protonated MC- $\mathbf{H}^{+}$(a) and deprotonated MC-H ${ }^{+}$(b) forms (relative Gibbs energies calculated at the DFT level are given in $\mathrm{kcal} \mathrm{mol}^{-1}$ ) a) positive ionization

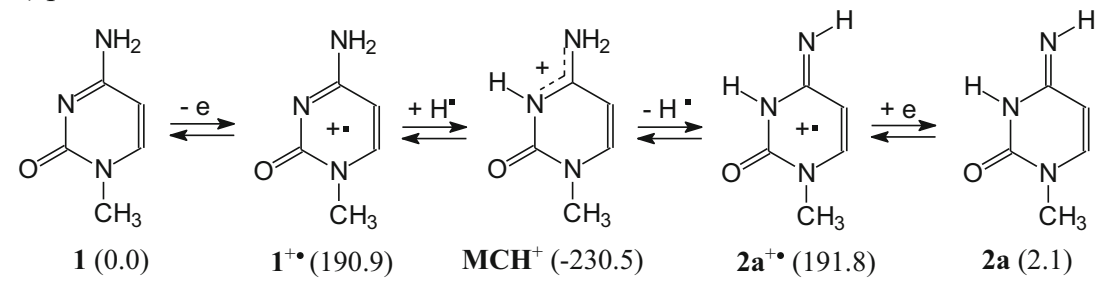

b) negative ionization

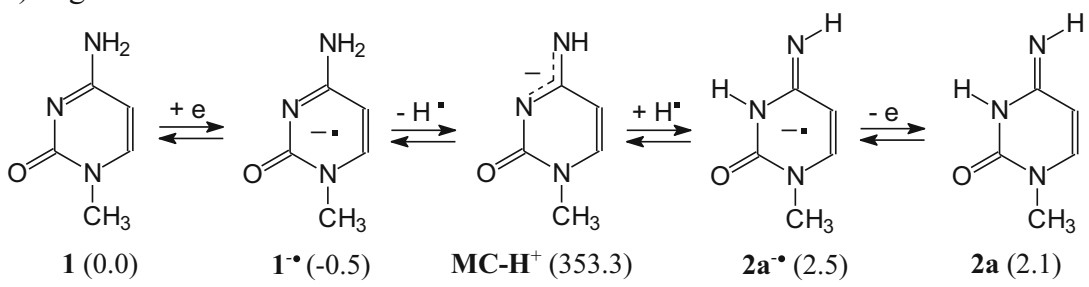


Scheme 6 Multi-steps conversion considered in the gas phase between isomers of 1 methylcytosine via the neutral radicals $\mathbf{M C}^{-\mathbf{H}^{*}}$ (a) and $\mathbf{M C H}^{*}$ (b) (relative Gibbs energies calculated at the DFT level are given in $\mathrm{kcal} \mathrm{mol}^{-1}$ )

a) positive ionization<smiles>Cn1ccc(=NN)n(C)c1=O</smiles>

b) negative ionization<smiles>Cn1c(C2CC2)cc(N)nc1=O</smiles>

$1(0.0)$<smiles>C=C[C+]1CNc2nc(=O)n(C)cc21</smiles>

$\mathbf{1}^{\bullet}(-0.5)$<smiles></smiles>

$\mathbf{M C H}^{\bullet}(-350.0)$<smiles></smiles>

$2 \mathbf{a}^{-\bullet}(2.5)$<smiles>Cn1ccc(=N)[nH]c1=O</smiles>

2a $(2.1)$ $\mathbf{3 b}$ and $\mathbf{3 d}$ with unfavorable interactions between $\mathrm{OH}$ and $\mathrm{Me}$ groups.

In the gas phase, which models apolar environments (lipids), positive or negative ionization does not change the tautomeric preference (Scheme 1). Ionization influences the isomeric mixture. The canonical isomer $\mathbf{1}$ is favored for $\mathbf{M C}, \mathbf{M C}^{+\bullet}$, and $\mathbf{M C}^{-\bullet}$. The rare isomer $\mathbf{2 a}$, responsible for DNA mutation [31], appears in detectable amounts in the isomeric mixture of $\mathbf{M C}$, $\mathbf{M C}^{+\bullet}$, and $\mathbf{M C}^{-\bullet}$ with the highest contribution for $\mathbf{M C}^{+\bullet}$. Its percentage content increases in aqueous solution, which models a more polar environment (enzymes, receptors, proteins, nucleoproteins, etc.). The rare isomer $\mathbf{2 a}$ becomes the favored form for $\mathbf{M C}^{+\bullet}$, while the canonical tautomer $\mathbf{1}$ is only a minor form. For $\mathbf{M \mathbf { C } ^ { - }}{ }^{-}$, the percentage contents of the radical anions $\mathbf{4 a - 5 b}$ are larger than that of $\mathbf{2 a}$. They are well stabilized by an unpaired electron. Polarity of water does not affect their contributions in the isomeric mixture. Positive ionization strongly increases the energies of $\mathbf{4 a - 5} \mathbf{b}$ such that they can be neglected in the isomeric mixture of $\mathbf{M C}^{+\bullet}$. For neutral $\mathbf{M C}$, they do not exist. Four rotamers of $\mathbf{3}$ can be neglected at each oxidation state in both extreme environments.

The most important effects observed for tautomeric 1methylcytosine seem to result from interactions of $\mathbf{M C}$ with positively ionized agents. They are completely different from those observed previously for isolated cytosine and better describe some tendencies of cytosine included in DNA to intramolecular proton-transfer than isolated cytosine. Interestingly, gas-phase acidities of radical cations of MC are close to that of its monocation, and gas-phase basicities of radical anions are close to that of its monoanion. Water in the gas phase is too weak a base to deprotonate $\mathbf{M C}^{+\bullet}$ and also it is too weak an acid to protonate $\mathbf{M C}^{-\bullet}$. This observation suggests that radical ions may live a longer time in an apolar than polar environment and may be responsible for changes in nucleic acids. Figure 7 summarizes the DFT-calculated relative Gibbs energies of possible structures which 1-methylcytosine may adopt when proceeding from the canonical to rare isomer.

Open Access This article is distributed under the terms of the Creative Commons Attribution 4.0 International License (http:// creativecommons.org/licenses/by/4.0/), which permits unrestricted use, distribution, and reproduction in any medium, provided you give appropriate credit to the original author(s) and the source, provide a link to the Creative Commons license, and indicate if changes were made.

\section{References}

1. Kaiser ET, Kevan L (Eds) (1968) Radical ions. Wiley, New York

2. Carey FA, Sundberg RJ (1993) Advanced organic chemistry, 3rd edn. Plenum, New York

3. Linstrom PJ, Mallard WG, Eds. NIST Chemistry WebBook, NIST Standard Reference Database No. 69, National Institute of Standards and Technology, Gaithersburg, MD, http://webbook. nist.gov/chemistry (retrieved April 15, 2016)

4. Hunt DF, Stafford GC Jr, Crow FW, Russell JW (1976) Pulsed positive negative ion chemical ionization mass spectrometry. Anal Chem 48:2098-2104

5. Tureček F (2003) Transient intermediates of chemical reactions by neutralization-reionization mass spectrometry. Top Curr Chem 225:77-129

6. Tureček F (1998) Modeling nucleobase radicals in the mass spectrometer. J Mass Spectrom 33:779-795

7. Muller-Dethlefs K, Schlag EW (1998) Chemical applications of zero kinetic energy (ZEKE) photoelectron spectroscopy. Angew Chem Int Ed 37:1346-1374

8. Sugawara K, Miyawaki J, Nakanaga T, Takeo H, Lembach G, Djafari S, Barth HD, Brutschy B (1996) Infrared depletion spectroscopy of the aniline dimer. J Phys Chem 100:17145-17147

9. Wu RH, Brutschy B (2004) Infrared depletion spectroscopy and structure of the 2-aminopyridine dimer. J Phys Chem A 108: 9715-9720

10. Choi J, Cho DW, Tojo S, Fujitsuka M, Majima T (2015) Structural study of various substituted biphenyls and their radical anions 
based on time-resolved resonance Raman spectroscopy combined with pulse radiolysis. J Phys Chem A 119:851-856

11. Fujitsuka M, Cho DW, Choi J, Tojo S, Majima T (2015) Detection of structural changes upon one electron oxidation and reduction of stilbene derivatives by time-resolved resonance Raman spectroscopy during pulse radiolysis and theoretical calculations. J Phys Chem A 119:6816-6822

12. Choi J, Yang C, Fujitsuka M, Tojo S, Ihee H, Majima T (2015) Proton transfer of guanine radical cations studied by time-resolved resonance Raman spectroscopy combined with pulse radiolysis. J Phys Chem Lett 6:5045-5060

13. Sevilla MD, Kumar A, Adhikary A (2016) Comment on "Proton transfer of guanine radical cations studied by time-resolved resonance Raman spectroscopy combined with pulse radiolysis". J Phys Chem B 120:2984-2986

14. Choi J, Yang C, Fujitsuka M, Tojo S, Ihee H, Majima T (2016) Reply to "Comment on 'Proton transfer of guanine radical cations studied by time-resolved resonance Raman spectroscopy combined with pulse radiolysis'". J Phys Chem B 120:2987-2989

15. Riestra-Kiracofe JC, Tschumper GS, Schaefer HF, Nandi S, Ellison GB (2002) Atomic and molecular electron affinities: photoelectron experiments and theoretical computations. Chem Rev 102:231-282

16. Wetmore SD, Russell JB, Eriksson LA (2000) Electron affinities and ionization potentials of nucleotide bases. Chem Phys Lett 322: 129-135

17. Walch SP (2003) Model calculations of the electron affinities and ionization potentials of DNA. Chem Phys Lett 374:496-500

18. Li XF, Cai ZL, Sevilla MD (2002) DFT calculations of the electron affinities of nucleic acid bases: dealing with negative electron affinities. J Phys Chem A 106:1596-1603

19. Close DM (2004) Calculation of the ionization potentials of the DNA bases in aqueous medium. J Phys Chem A 108:1037610379

20. Kim S, Schaefer HF (2010) Vertical detachment energies of abionic thymidine. Microhydration effects. J Chem Phys 133: 144305

21. Gu J, Xie Y, Schaefer HF (2014) Benchmarking the electron affinity of uracil. J Chem Theory Comput 10:609-612

22. Raczyńska ED, Kosińska W, Ośmiałowski B, Gawinecki R (2005) Tautomeric equilibria in relation to pi-electron delocalization. Chem Rev 105:3561-3612, and references cited therein

23. Li X, Bowen KH, Haranczyk M, Bachorz RA, Mazurkiewicz K, Rak J, Gutowski M (2007) Photoelectron spectroscopy of adiabatically bound valence anions of rare tautomers of the nucleic acid bases. J Chem Phys 127:174309

24. Raczyńska ED, Makowski M, Hallmann M, Kamińska B (2015) Geometric and energetic consequences of prototropy for adenine and its structural models - a review. RSC Adv 5:36587-36604

25. Raczyńska ED, Zientara K, Kolczyńska K, Stępniewski TM (2009) Change of prototropic equilibria for uracil when going from neutral molecule to charged radicals. Quantum-chemical studies in the gas phase. Pol J Chem 83:821-834

26. Raczyńska ED, Makowski M, Zientara-Rytter K, Kolczyńska K, Stępniewski TM, Hallmann M (2013) Quantum-chemical studies on the favored and rare tautomers of neutral and redox adenine. $\mathrm{J}$ Phys Chem A 117:1548-1559

27. Raczyńska ED (2014) Electron delocalization and relative stabilities for the favored and rare tautomers of hydroxyazines in the gas phase - a comparison with aminoazines. Comput Theor Chem 1042:8-15

28. Raczyńska ED, Sapuła M, Zientara-Rytter K, Kolczyńska K, Stępniewski TM, Hallmann M (2016) DFT studies on the favored and rare tautomers of neutral and redox cytosine. Struct Chem 27: 133-143, and references cited therein
29. Pauling L (1939) First Edn (1940) Second Edition (1960) Third Edition The nature of chemical bond. Cornell University Press, New York

30. Watson JD, Crick FHC (1953) Molecular structure of nucleic acids. A structure of deoxyribose nucleic acid. Nature 171:737738

31. Watson JD, Crick FHC (1953) Genetical implications of the structure of deoxyribonucleic acid. Nature 171:964-967

32. Kumar A, Sevilla MD (2010) Proton-coupled electron transfer in DNA on formation of radiation-produced ion radicals. Chem Rev 110:7002-7023

33. Löwdin P-O (1963) Proton tunneling in DNA and its biological implications. Rev Mod Phys 35:724-731

34. Löwdin P-O (1965) Quantum genetics and the aperiodic solid: some aspects on the biological problems of heredity, mutations, aging, and tumors in view of the quantum theory of the DNA molecule. Adv Quantum Chem 2:213-360

35. Florián J, Leszczyński (1996) Spontaneous DNA mutations induced by proton transfer in the guanine-cytosine base pairs: an energetics perspective. J Am Chem Soc 118:3010-3017

36. Podolan Y, Grob L, Leszczyński J (2003) Ab initio study of the prototropic tautomerism of cytosine and guanine and their contribution to spontaneous point mutations. Int J Mol Sci 4:410-421

37. Hobza P, Šponer J (1999) Structure, energetics, and dynamics of the nucleic acid base pairs. Nonempirical ab initio calculations. Chem Rev 99:3247-3276

38. Danilov VI, Stewart JJP, Leś A, Alderfer JL (2000) A theoretical study of pyrimidine photohydrates and a proposed mechanism for the mutagenic effect of ultraviolet light. Chem Phys Lett 328:75-82

39. Danilov VI, Anisimov VM, Kurita N, Hovorun D (2005) MP2 and DFT studies of the DNA rare base pairs: the molecular mechanism of the spontaneous substitution mutations conditioned by tautomerism of bases. Chem Phys Lett 412:285-293

40. Grebneva HA (2003) Nature and possible mechanisms of formation of potential mutations arising at emerging of thymine dimers after irradiation of double-stranded DNA by ultraviolet light. J Mol Struct 105:133-143

41. Kryachko ES (2002) The origin of spontaneous point mutations in DNA via Löwdin mechanism of proton tunneling in DNA base pairs: cure with covalent base pairing. Int J Quantum Chem 90: 910-923

42. Villani G (2010) Theoretical investigation of hydrogen atom transfer in the cytosine-guanine base pair and its coupling with electronic rearrangement. Concerted vs. stepwise mechanism. J Phys Chem B 114:9653-9662

43. Cerón-Carrasco JP, Requena A, Perpète EA, Michaux C, Jacquemin D (2010) Theoretical study of the tautomerism in the one-electron oxidized guanine-cytosine base pair. J Phys Chem B 114:13439-13445

44. Jacquemin D, Zúñiga J, Requena A, Cerón-Carrasco JP (2014) Assessing the importance of proton transfer reactions in DNA. Acc Chem Res 47:2467-2474

45. Cerón-Carrasco JP, Jacquemin D (2015) DNA spontaneous mutation and its role in the evolution of GC-content: assessing the impact of the genetic sequence. Phys Chem Chem Phys 17: $7754-7760$

46. Brovarets OO, Kolomiets IM, Hovorun DM (2012) Elementary molecular mechanisms of the spontaneous point mutations in DNA: a novel quantum-chemical insight into the classical understanding. In Quantum Chemistry - Molecules for Innovations, Tada T (Ed), In Tech Open Access, Rijeka, pp. 59-102

47. Brovarets OO, Hovorun DM (2015) New structural hypostases of the A-T and G-C Watson-Crick DNA base pairs caused by their mutagenic tautomerism in a wobble manner: a QM/QTAIM prediction. RSC Adv 5:99594-99605 
48. Turaeva N, Brown-Kennerly V (2015) Marcus model of spontaneous point mutation in DNA. Chem Phys 461:106-110

49. Godbeer AD, Al-Khalili JS, Stefevenson PD (2015) Phys Chem Chem Phys 17:13034-13044

50. Gu J, Xie Y, Schaefer HF (2007) Electron attachment induced proton transfer in a DNA nucleoside pair: 2'-deoxyguanosine-2'deoxycytidine. J Chem Phys 127:155107

51. Gu J, Xie Y, Schaefer HF (2009) Electron attachment to oligonucleotide dimmers in water: microsolvation-assisted base-stacking forms. Chem Phys Lett 473:213-219

52. Kumar A, Sevilla MD (2009) Influence of hydration on proton transfer in the guanine-cytosine radical cation $\left(\mathrm{G}^{+}{ }^{-} \mathrm{C}\right)$ base pair: a density functional theory study. J Phys Chem B 113:11359-11361

53. Kumar A, Adhikary A, Shamoun L, Sevilla MD (2016) Solvated electrons $\left(\mathrm{e}_{\mathrm{aq}}{ }^{-}\right)$reduce DNA bases? A Gaussian 4 and density functional theory - Molecular dynamics study. J Phys Chem B 120:2115-2123

54. Hsu SCN, Wang T-P, Kao C-L, Chen H-F, Yang P-Y, Chen H-Y (2013) Theoretical study of the protonation of the one-electron reduced guanine-cytosine base pair by water. J Phys Chem B 117:2096-2105

55. Lin S-H, Fujitsuka M, Majima T (2015) How does guaninecytosine base pair affect excess-electron transfer in DNA? J Phys Chem B 119:7994-8000

56. Adhikary A, Kumar A, Becker D, Sevilla MD (2006) The guanine cation radical investigation of deprotonation states by ESR and DFT. J Phys Chem B 110:24171-24180

57. Raczyńska ED, Gal J-F, Maria P-C, Zientara K, Szelag M (2007) Application of FT-ICR-MS for the study of proton-transfer reactions involving biomolecules. Anal Bioanal Chem 389:13651380

58. Raczyńska ED, Cyrański MK, Gutowski M, Rak J, Gal J-F, Maria P-C, Darowska M, Duczmal K (2003) Consequences of proton transfer in guanidine. J Phys Org Chem 16:91-106

59. Yang B, Moehlig AR, Frieler CE, Rodgers MT (2015) Basepairing energies of protonated nucleobase pairs and proton affinities of 1-methylated cytosines: model systems for the effects of the sugar moiety on the stability of DNA i-motif. J Phys Chem B 119:1857-1868

60. Keane PM, Wojdyla M, Doorley GW, Watson GW, Clark IP, Greetham GM, Parker AW, Towrie M, Kelly JM, Quinn SJ (2011) A comparative picosecond transient infrared study of 1methylcytosine and 5'-dCMP that sheds further light on the excited states of cytosine derivatives. J Am Chem Soc 133: 4212-4215

61. Szyperska A, Rak J, Leszczynski J, Li X, Ko YJ, Wang HP, Bowen KH (2009) Valence Anions of 9-methylguanine-1methylcytosine complexes. Computational and photoelectron spectroscopy studies. J Am Chem Soc 131:2663-2669, Erratum 6641-6641

62. Chen HY, Hsu SCN, Kao CL (2010) Microhydration of 9methylguanine-1-methylcytosine base pair and its radical anion: a density functional theory study. Phys Chem Chem Phys 12: 1253-1263

63. Ko YJ, Wang HP, Radisic D, Stokes ST, Eustis SN, Bowen KH, Mazurkiewicz K, Storoniak P, Kowalczyk A, Harańczyk M, Gutowski M, Rak J (2010) Barrier-free proton transfer induced by electron attachment to the complexes between 1methylcytosine and formic acid. Mol Phys 108:2621-2631

64. Cerny J, Hobza P (2010) Energy barriers between H-bonded and stacked structures of 9-methyladenine-1-methylthymine and 9methylguanine-1-methylcytosine complexes. Chem Commun 46:383-385

65. Parr RG, Yang W (1998) Density functional theory of atoms and molecular orbital theory. Oxford University Press, New York
66. Becke AD (1993) Density-functional thermochemistry. III. The role of exact exchange. J Chem Phys 98:5648-5652

67. Lee C, Yang W, Parr RG (1988) Development of the ColleSalvetti correlation-energy formula into a functional of the electron density. Phys Rev B 37:785-789

68. Hehre WJ, Radom L, Schleyer PR, Pople JA (1986) Ab initio molecular theory. Wiley, New York

69. Miertus S, Tomasi J (1982) Approximate evaluation of the electrostatic free energy and internal energy changes in solution processes. Chem Phys 65:239-241

70. Miertus S, Scrocco E, Tomasi J (1981) Electrostatic interaction of a solute with a continuum. A direct utilization of ab initio molecular potentials for the prevision of solvent effects. Chem Phys 55:117-129

71. Woon DE, Dunning TH (1993) Gaussian basis sets for use in correlated molecular calculations. III. The atoms aluminum through argon. J Chem Phys 98:1358-1371

72. Maksić ZB, Kovačević B, Vianello R (2012) Advances in determining the absolute proton affinities of neutral organic molecules in the gas phase and their interpretation: a theoretical account. Chem Rev 112:5240-5270

73. Leito I, Koppel IA, Koppel I, Kaupmees K, Tshepelevitsh S, Saame J (2015) Basicity limits of neutral organic superbases. Angew Chem Int Ed 54:9262-9265

74. Rodríguez-Santiago L, Vendrell O, Tejero I, Sodupe M, Bertran J (2001) Solvent-assisted catalysis in the enolization of acetaldehyde radical cation. Chem Phys Lett 334:112-118

75. Lammertsma K, Prasad BV (1994) Imine $\rightarrow$ enamine tautomerism. J Am Chem Soc 116:642-650

76. Fogarasi GJ (2010) Studies on tautomerism. Benchmark quantum chemical calculations on formamide and formamidine. J Mol Struct 978:257-262

77. Ośmiałowski B, Raczyńska ED, Krygowski TM (2006) Tautomeric equilibria and pi electron delocalization for some monohydroxyarenes - quantum chemical studies. J Org Chem 71:3727-3736

78. Raczyńska ED, Kolczyńska K, Stępniewski TM (2011) Tautomeric preferences and pi-electron delocalization for redox forms of phenol. Comput Theor Chem 963:176-184

79. Raczyńska ED, Stępniewski TM, Kolczyńska K (2011) Consequences of one-electron oxidation and one-electron reduction for aniline. J Mol Model 17:3229-3239

80. Raczyńska ED, Stępniewski TM, Kolczyńska K (2012) DFT studies on one-electron oxidation and one-electron reduction for 2- and 4-aminopyridines. J Mol Model 18:4367-4380

81. Raczyńska ED, Kolczyńska K, Stępniewski TM (2012) Consequences of one-electron oxidation and one-electron reduction for 4-aminopyrimidine - DFT studies. J Mol Model 18:35233533

82. Raczyńska ED (2012) Quantum-chemical studies of the consequences of one-electron oxidation and one-electron reduction for imidazole in the gas phase and water. Comput Theor Chem 993: 73-79

83. Lin XJ, Wang Q, Wu J, Liu CB (2008) DFT study on the mechanism of DNA damage caused by the isomerization of DNA purine base. J Theor Comput Chem 7:457-472

84. Shukla MK, Leszczynski J (2010) Comprehensive evaluation of medium and long range correlated density functionals in TD-DFT investigation of DNA bases and base pairs: gas phase and water solution study. Mol Phys 108:3131-3146

85. Shanmugasundaram M, Puranik M (2011) Vibrational markers of structural distortion in adenine nucleobases upon DNA damage. Phys Chem Chem Phys 13:3851-3862

86. Frisch MJ, Trucks GW, Schlegel HB, Scuseria GE, Robb MA, Cheeseman JR, Montgomery JA Jr, Vreven T, Kudin KN, Burant JC, Millam JM, Iyengar SS, Tomasi J, Barone V, 
Mennucci B, Cossi M, Scalmani G, Rega N, Petersson R, Nakatsuji H, Hada M, Ehara M, Toyota K, Fukuda R, Hasegawa J, Ishida M, Nakajima T, Honda Y, Kitao O, Nakai H, Klene M, Li X, Knox JE, Hratchian HP, Cross JB, Bakken V, Adamo C, Jaramillo R, Gomperts R, Stratmann RE, Yazyev O, Austin AJ, Cammi R, Pomelli C, Ochterski JW., Ayala PY, Morokuma K, Voth GA, Salvador P, Dannenberg JJ, Zakrzewski VG, Dapprich S, Daniels AD, Strain MC, Farkas O, Malick DK, Rabuck AD, Raghavachari K, Foresman JB, Oritz JV, Cui Q, Baboul AG, Clifford S, Cioslowski J, Stefanov BB, Liu G, Liashenko A, Piskorz P, Komaromi I, Martin RL, Fox DJ, Keith T, Al-Laham MA, Peng CY, Nanayakkara A, Challacombe M, Gill PMW, Johnson B, Cheng, Wong MW, Gonzalez C, Pople JA (2004) Gaussian-03, revision E.01. Gaussian Inc., Wallingford

87. Raczyńska ED, Krygowski TM, Duczmal K, Hallmann M (2006) On geometry-based HOMED (a measure of hyperconjugation, n$\pi$, and $\pi-\pi$ conjugation) and HOMA index (a measure of aromaticity). XVIII International Conference on Physical Organic Chemistry, Warsaw (Book of abstracts, p. 31)

88. Raczyńska ED, Hallmann M, Kolczyńska K, Stępniewski TM (2010) On the harmonic oscillator model of electron delocalization (HOMED) index and its application to heteroatomic $\pi$ electron systems. Symmetry 2:1485-1509

89. Kruszewski J, Krygowski TM (1972) Definition of aromaticity basing on the harmonic oscillator model. Tetrahedron Lett 13: 3839-3842

90. Krygowski TM, Kruszewski J (1974) Aromaticity of thiophene, pyrrole and furan in terms of aromaticity indices and Hammett $\rho$ constants. Bull Acad Pol Sci, Sér Sci Chim 22:871-876

91. Krygowski TM (1993) Crystallographic studies of inter- and intramolecular interactions reflected in aromatic character of $\pi$ electron systems. J Chem Inf Comput Sci 33:70-78

92. Frizzo CP, Martin MP (2012) Aromaticity in heterocycles: new HOMA index parameterization. Struct Chem 23:375-380

93. Harańczyk M, Rak J, Gutowski M (2005) Stabilization of very rare tautomers of 1-methylcytosine by an excess electron. J Phys Chem A 109:11495-11503

94. Alonso JL, Vaquero V, Peña I, López JC, Mata S, Caminati W (2013) All five forms of cytosine revealed in the gas phase. Angew Chem Int Ed 52:2331-2334

95. Szczesniak M, Leszczynski J, Person WB (1992) Identification of the imino-oxo form of 1-methylcytosine. J Am Chem Soc 114: 2731-2733

96. Smets J, Houben L, Schoone K, Maes G, Adamowicz L (1996) Multiple site proton affinities of methylated nucleic acid bases. Chem Phys Lett 262:789-796

97. Liu M, Li T, Amegayibor FS, Cardoso DS, Fu Y, Lee JK (2008) Gas-phase themochemical properties of pyrimidine nucleobases. J Org Chem 73:9283-9291

98. Tureček F, Yao CX (2003) Hydrogen atom addition to cytosine, 1methylcytosine, and cytosine-water complexes. A computational study of a mechanistic dichotomy. J Phys Chem A 107: 9221-9231

99. Yao CX, Cuadrado-Peinado ML, Polášek M, Tureček F (2005) Gas-phase tautomers of protonated 1-methylcytosine. Preparation, energetics, and dissociation mechanisms. J Mass Spectrom 40:1417-1428
100. Reva I, Nowak MJ, Lapinski L, Fausto R (2012) UV-Induced amino $\rightarrow$ imino hydrogen-atom transfer in 1-methylcytosine. J Phys Chem B 116:5703-5710

101. Li Q, Blancafort L (2013) Photochemistry and photophysics of the amino and imino tautomers of 1-methylcytosine: tautomerisation as a side product of the radiationless decay. Photochem Photobiol Sci 12:1401-1408

102. Close DM, Eriksson LA, Hole EO, Sagstuen E, Nelson WH (2000) Experimental and theoretical investigation of the mechanism of radiation-induced radical formation in hydrogen-bonded cocrystals of 1-methylcytosine and 5-fluorouracil. J Phys Chem B 104:9343-9350

103. Geimer J, Hildenbrand K, Naumov S, Beckert D (2000) Radicals formed by electron transfer from cytosine and 1-methylcytosine to the triplet state of anthraquinone-2,6-disulfonic acid. A Fouriertransform EPR study. Phys Chem Chem Phys 2:4199-4206

104. Dolgounitcheva O, Zakrzewski VG, Oritz JV (2003) Ionization energies and dyson orbitals of cytosine and 1-methylcytosine. J Phys Chem A 107:822-828

105. Huang YQ, Kenttamaa H (2003) Theoretical and experimental investigations on the chemical reactions of positively charged phenyl radicals with cytosine and 1-methylcytosine. J Am Chem Soc 125:9878-9889

106. Yao CX, Cuadrado-Peinado ML, Polášek M, Tureček F (2005) Specific generation of 1-methylcytosine radicals in the gas phase. Angew Chem Int Ed 44:6708-6711

107. Adhikary A, Kumar A, Bishop CT, Wiegand TJ, Hindi RM, Adhikary A, Sevilla MD (2015) $\pi$-Radical to $\sigma$-radical tautomerization in one-electron-oxidized 1-methylcytosine and its analogs. J Phys Chem B 119:11496-11505

108. Michalkova A, Kosenkov D, Grob L, Leszczynski J (2008) Thermodynamics and kinetics of intramolecular water assisted proton transfer in $\mathrm{Na}^{+}-1$-methylcytosine water complexes. $\mathrm{J}$ Phys Chem B 112:8624-8633

109. Miguel PJS, Lax P, Willerman M, Lippert B (2004) Coexistance of major and minor tautomers of 1-methylcytosine $(1-\mathrm{MeC})$ in a single metal complex, trans-Pt(1-MeC-N3)(1-MeC-N4) $\mathrm{X}_{2}$ $(\mathrm{X}=\mathrm{Cl}, \mathrm{I})$ : metal migration $\mathrm{N} 3 \rightarrow \mathrm{N} 4$ at acidic $\mathrm{pH}$. Inorg Chim Acta 357:4552-4561

110. Montagner D, Zangrando E, Longato B (2009) Stabilization of the iminooxo tautomer of 1-methylcytosine in $\mathrm{PT}^{\mathrm{II}}$ complexes: role of the ancillary ligands. Inorg Chim Acta 362:725-732

111. Dougherty D, Younathan ES, Voll R, Abdulnur S, McGlynn SP (1978) Photoelectron spectroscopy of some biological molecules. J Electron Spectrosc Relat Phenom 13:379-393

112. Schiedt J, Weinkauf R, Neumark DM, Schlag EW (1998) Anion spectroscopy of uracil, thymine and the amino-oxo and aminohydroxy tautomers of cytosine and their water clusters. Chem Phys 239:511-524

113. Nenner I, Schultz GJ (1975) Temporary negative ions and electron affinities of benzene and $\mathrm{N}$-heterocyclic molecules: pyridine, pyridazine, pyrimidine, pyrazine, and s-triazine. J Chem Phys 62:1747-1758

114. Gal J-F, Maria P-M, Raczyńska ED (2001) Thermochemical Aspects of Proton Transfer in the Gas Phase. J Mass Spectrom 36:699-716 